\title{
PAULO FREIRE EN ARGENTINA Y SUS LEGADOS EN LA EDUCACIÓN POPULAR
}

PAULO FREIRE IN ARGENTINA AND HIS LEGACIES IN POPULAR EDUCATION

\author{
Inés Fernández Mouján ${ }^{1}$ \\ Universidad Nacional de Mar del Plata, Argentina
}

Resumen: Historiar el término educación popular permite comprender de manera cabal el sentido que adquirió la educación en Argentina. Para lograr una profundización en este debate propongo deconstruir y someter a crítica los sentidos de la educación popular para demostrar como en la tradición que inaugura Paulo Freire en 1963 en Angicos podemos encontrar su potencial y su carácter transformador. En síntesis, la línea de análisis somete a crítica la idea de educación popular en el inicio de la constitución del Estado de la Nación Argentina (Siglo XIX), desde enfoque que entrelaza lo que hay de descriptivo y que permanece en las tradiciones con un proceso mediante el cual algunas cosas se prefieren y destronan a otras. El foco está puesto en la tradición freireana, cómo ésta ubica en el centro de la escena educativa al sujeto oprimido, y la relación entre lo cultural y lo político. La intención es observar en las experiencias de educación popular argentinas los debates que habilitaron acciones resistentes a la colonialidad del poder-saber presentes en la educación como lo fue la Campaña de Reactivación de Educación de Adultos para la Reconstrucción (1974-1976) y luego realizar una análisis del presente de la educación popular en la Argentina.

Palabras claves: Paulo Freire, Argentina, educación popular, lo político, lo cultural.

Abstract: Historicizing the term popular education allows us to fully understand the meaning that education acquired in Argentina. In order to deepen this debate, I propose to deconstruct and criticize the senses of popular education to demonstrate how in the tradition that Paulo Freire inaugurated in 1963 in Angicos we can find its potential and its transforming character. In summary, the line of analysis criticizes the idea of popular education at the beginning of the constitution of the Argentine Nation State (19th century), from an approach that intertwines what is descriptive and that remains in the traditions with a process through which

\footnotetext{
${ }^{1}$ Facultad de Ciencias de la Salud y Trabajo Social, Cátedra Paulo Freire, Universidad Nacional de Mar del Plata, Argentina. E-mail: imoujan@gmail.com
} 
some things are preferred and dethrone others. The focus is on the Freireian tradition, how it places the oppressed subject at the center of the educational scene, and the relationship between the cultural and the political. The intention is to observe in the experiences of popular education in Argentina the debates that enabled actions resistant to the coloniality of power-knowledge present in education as was the Campaign for the Reactivation of Adult Education for Reconstruction (1974-1976), and then carry out an analysis of the present of popular education in Argentina.

Keywords: Paulo Freire, Argentina, educación popular education, political, cultural.

Recebido em: 04/11/2019

Aprovado em: 02/03/2020

Publicado em: 11/04/2020

\section{INTRODUCCIÓN}

Me pregunto ¿(Re)visitar legados y tradiciones nos puede habilitar caminos posibles para resignificar prácticas y la apertura de nuevos horizontes en la educación? Entiendo que por este camino andan (principalmente) los movimientos populares, multiplicando acciones marchan y reclaman por una educación que contemple territorios, culturas y voces contra-hegemónicas. Tengo la firme convicción que la educación popular en la tradición freireana y latinoamericana, en tanto intervención pedagógica-política es expresión de una identidad histórica y cultural, al mismo tiempo que un aporte a la resistencia política en nuestro continente americano.

Mi propuesta es pensar más allá de las narrativas originales o iniciales para entrometerme en los entre-medio y concentrarme en " [...] los procesos que se producen en la articulación de las diferencias culturales." (BHABHA, 2017, p. 18); y observar cómo la praxis freireana es una práctica teorético-crítica de resistencia-negociación-tensión entre el dominio y la subordinación. Me propongo revisar los alcances y analizar brevemente sobre la historia de la educación popular en nuestra Argentina a partir de la constitución de la Estado-Nación y las marcas raciales que portó el proyecto sarmientino, para luego, situar los debates que se plantearon con la irrupción del pensamiento de Paulo Freire en la escena 
educativa argentina a mediados del siglo XX en adelante. En este punto hago foco la Campaña de Reactivación de Educación de Adultos para la Reconstrucción (CREAR, 1974-1976) y finalmente ubico la actualidad de estos debates.

\section{EL LEGADO DE DOMINGO FAUSTINO SARMIENTO: LA EDUCACIÓN Y SU MARCA RACIAL}

En la historia de la educación argentina el concepto educación popular nos remite en primer lugar al legado sarmientino del siglo XIX en los inicios constitución del Estado Nación. La idea de educación popular fue sinónimo de instrucción pública en la Argentina. Ésta puede ubicarse en el propósito de instruir al pueblo para lograr el progreso general de la Nación, "condición necesaria para conformar una nueva subjetividad que siente sus bases en la idea de un ciudadano moderno activo y libre". Estos fundamentos se expresaron en dos lemas: "civilización y barbarie" y "orden y progreso", en tanto principios organizadores subordinaron la libertad al orden. Así, en los inicios del sistema educativo argentino, la instrucción pública fue sinónimo de educación popular e hizo referencia a un proyecto cuyo fin fue "educar al soberano", pero desde una operatoria de sistemática exclusión-negación-racialización de las poblaciones originarias de nuestras tierras (FERNÁNDEZ MOUJÁN, 2019, p. 121). Mi interpretación es que en este proyecto de educación popular sarmientino una voluntad homogeneizadora, cuyo objetivo es civilizar, silenciar y obliterar, para construir una nación de ciudadanos unidos por un idioma, una historia, un sistema educativo que contribuya a conformar una identidad homogénea y única, igualitaria para establecer así una comunidad de sentido (AÑÓN y RUFER, 2018; TENTI FANFANI, 2007; PUIGGRÓS, 1990). Educación que desde los inicios del sistema educativo argentino estuvo estrechamente ligada a la proyecto de la Modernidad.

Ahora bien, si considero este análisis entiendo que el significante educación (en el decir de Michel Trouillot) es un término turbio de la familia de los "universales noratlánticos" (TROUILLOT, 2011), en tanto que universal noratlántico se estableció a partir de pedazos de

\footnotetext{
2 Frase acuñada por Domingo Faustino Sarmiento y que condensa su posición de ilustrado.
} 
la historia de la humanidad y se convirtió en estándar histórico, que desconoció, negó y silenció , “[...] a los muchos Otros.” (TROUILLOT, 2011, p. 81). Los universales noratlánticos, tal como lo sostiene Trouillot, no son descripciones ingenuas sino que ofrecen visiones del mundo que niegan las localización, las sensibilidades y la historia desde la cual emergen. Siempre prescriptivos, los universales noratlánticos sugieren, el estado correcto de las cosas, es decir una moral, un conocimiento, un hacer las cosas correctamente y un deber. Una seducción que resulta muchas veces irresistible. "Si la seducción de los universales noratlánticos radica en su poder de silenciar su propia historia, nuestra tarea inmediata es desenterrar esos silencios."(TROUILLOT, 2011, p. 82).

Otro problema que resulta necesario destacar en el proyecto educativo moderno en la Argentina (y en los países coloniales) es el silencio, olvido y borramiento de las identidades culturales desde donde se operó sistemáticamente para producir un vacío, una idea de tabla rasa sobre la cual erigir el presente y proyectar el futuro dentro del sistema educativo, estructura central del proyecto moderno. "“...] la colonialidad", en tanto persistencia configura una suerte de subtexto de la representación de identidades nacionales." (AÑÓN y RUFER, 2018, p. 114). El "silencio de lo colonial”, sostienen Valeria Añón y Mario Rufer (2018), opera como fundante en la configuración de nuestro relato educativo y así la exclusión, la negación, lo indecible se presentan como figuras que estructuran nuestras teorías-prácticas, en definitiva nuestras identidades. Al mismo tiempo que se banaliza y se trivializan acciones fundantes del Estado-Nación argentino como, por ejemplo, el genocidio indígena perpetrado en Argentina durante el siglo XIX. Lo que se presenta es un olvido necesario y funcional de lo colonial ${ }^{4}$, un tiempo vacío y homogéneo que resulta constitutivo de de nuestras instituciones. Lo que se presentan son ficciones fundacionales a las que se le suman silencios fundacionales (AÑÓN y RUFER, 2018, p.115-116). A partir de este análisis

\footnotetext{
3 Se hace referencia a la noción de "colonialidad del poder "Aníbal Quijano (2000) y en la tradición de la idea de "capitalismo racial" propuesta por Cedric J. Robinson (1983). Ahora bien, la colonialidad del poder es un concepto que implica algunas ideas centrales: racismo, poder como red de relaciones; heterogeneidad estructural y totalidad. Es decir que, no es posible comprender el modo en que existe una determinada formación social y la manera en que opera el poder que la configura, si no se analizan las formas históricas en que se dan las relaciones de dominación/explotación/conflicto que articulan las disputas en sus diversos ámbitos, y si no se tiene en cuenta la heterogeneidad de relaciones de determinación que definen su comportamiento.

Lo colonial término en el que me referiré para designar una trama compleja de prácticas (simbólicas y materiales) que garantizan la subordinación de grupos sociales. Una práctica de poder-saber, cuya capacidad de representar afecta los modos de organización social de pueblos colonizados, e inscribe sus formas de productividad, como así también las resistencias "En las historias americanas la palabra despliega de manera específica procesos de producción de la subjetividad muy profundos que articulan en combinaciones específicas de la raza, el género, la clase y el sexo" (DE OTO y CATELLI, 2018, p. 232).
} 
me pregunto: ¿Qué relaciones se puede establecer entre los "universales nor-atlánticos" (TROUILLOT, 2011) y el "silencio de lo colonial” (AÑÓN Y RUFER, 2018) con la idea de educación popular implícita en el proyecto de Sarmiento?

Pues bien en una lectura crítica de Facundo ${ }^{5}$ o Civilización i Barbarie (1874) se puede señalar que los presupuestos filosóficos del proyecto político de Domingo Faustino Sarmiento llevan implícitos una clasificación racial de la población argentina y que encuentra su sostén ideológico en la obra de Alexis Tocqueville La democracia en América ${ }^{6}$ (1835). El Facundo tiene como modelo político la democracia liberal que le propone Tocqueville, dice Sarmiento “[...] mi ánimo es sólo mostrar el nuevo orden de instituciones que suplantan a las que estamos copiando de la Europa." (SARMIENTO, 1874, p. 174). Este "nuevo orden", esta democracia liberal se estructura a partir de principios raciales (MBEMBE, 2012), sus fundamentos pueden sintetizarse en la siguiente afirmación: "La raza de hombres por excelencia es la blanca [...] primero en luces, en poder y felicidad, es el hombre blanco, el europeo, el hombre por excelencia [...] debajo están el negro y el indio [...] éstas son razas infortunadas, desgraciadas e inferiores", estos no tienen estatuto de humanidad." (1957, p. 312-313).

Ahora bien, detengámonos por un momento en ¿Quién era Domingo Faustino Sarmiento? Nace en la Provincia de San Juan, Argentina. Acompañó y participó activamente de la vida política ${ }^{7}$ en los inicios de la constitución del Estado-Nación, enemigo político de Juan Manuel de Rosas (1793-1877) y del caudillo riojano Facundo Quiroga (1788-1835). Fue

\footnotetext{
5 Sarmiento en el Facundo se construye a sí mismo de una manera muy precisa, es un texto que forma parte de su lucha política. Dicho de otro modo, lo que dinamiza su obra es la lucha por el poder. Sarmiento con el Facundo se propone ganar consenso para su proyecto político (TERÁN, 2015, p. 67-68). De allí que, el nombre Facundo refiere al caudillo argentino Facundo Quiroga; para Sarmiento éste encarna "un aspecto esencial de la realidad de su tiempo: la barbarie" (TERÁN, 2015, p. 70).

Ensayo filosófico político en el que desarrolla la teoría del Estado democrático. Traza en ella su teoría sobre la democracia y sus condiciones de posibilidad a partir del principio de igualdad. Tocqueville escribe en pleno auge del liberalismo, en un contexto en donde los Estados europeos consideran al resto del mundo como posesión al mismo tiempo que un mercado sin límites. El liberalismo, para Tocqueville, implica en su esencia una relación de producción/destrucción junto con la idea de libertad. En un estilo en sintonía con la tradición francesa del momento que plantea una igualdad formal que conlleva la idea de que solo es viable la vida democrática entre "blancos", es decir solo pueden tener estatuto de ciudadanos los hombres blancos. Este argumento principalmente lo desarrolla en el Capítulo X de la Democracia en América en donde sitúa:“Algunas consideraciones sobre el estado actual y el porvenir probable de las tres razas que habitan el territorio de los Estados Unidos". Su planteo consiste en justificar porque se hace necesario establecer una distancia social entre blancos por un lado y negros e indios por otro.

$7 \quad$ Ejerció importantes cargos políticos: primero la presidencia entre 1868-1874; luego en el gobierno de Nicolás Avellaneda fue Ministro de Justicia e Instrucción Pública de 1874-1880 y participó del gobierno de Julio Argentino Roca (1880-1886).
} 
un intelectual romántico e ilustrado, activo integrante de la llamada Generación del $37^{8}$. En sintonía con el proyecto político de Alexis Tocqueville para Sarmiento el mal y la barbarie eran el negro, el indio y el gaucho a los que consideró "males que se extendieron sobre la República” (SARMIENTO, 1874, p. 73) y que había que exterminar.

\begin{abstract}
¿Lograremos exterminar a los indios? Por los salvajes de América siento una invencible repugnancia sin poderlo remediar. Esa canalla no son más que unos indios asquerosos a quien mandaría colgar ahora si reapareciesen. [...] Incapaces de progreso, su exterminio es providencial y útil, sublime y grande. Se los debe exterminar sin siquiera perdonar al pequeño, que tiene ya el odio instintivo al hombre civilizado (SARMIENTO, 1874, apud DAVID, 2008: 60-61).
\end{abstract}

El señor Sarmiento "[...] tan criollo él con sus estallidos de furia exige para expiar el pecado de ser hijos de España que se derrame sangre barata de gaucho." (RIVERA, 2009, p. 34). Observemos ahora algunos puntos del Facundo, obra considerada de la más importantes en la historia de la literatura argentina, como indica Oscar Terán es un texto que marcó las producciones intelectuales y políticas del siglo XIX en Argentina (2015, p. 66). Desde sus páginas Sarmiento delineó su proyecto político (que quedará inconcluso) pero que preanuncia las ideas sobre la instrucción pública (TERÁN, 2015, p. 90). Principios que se plasmarán en la Ley de Educación común argentina a partir de la convicción de que para pensar cambios o reformas estructurales debía promoverse la escolarización masiva de una población sobre la que pesaba casi como una daga una fuerte desconfianza (Puiggrós, 1990). Sarmiento escribe desde la política entregas semanales en el Diario El Progreso (Chile) que luego las reunió en un ensayo de interpretación histórico-social, el Facundo, y que resultó sumamente eficaz como imposición de una serie de tópicos para pensar la realidad argentina. (TERÁN, 2015, p. 67). El Facundo es un libro que utiliza diversas estrategias argumentativas y está destinado a generar credibilidad por ello conjuga romanticismo con ideas ilustradas. Así por un lado, encontramos en varios pasajes como acude a una retórica romántica destinada a promover la sensibilidad, como cuando describe la pampa, su extensión, sus tormentas (TERÁN, 2015, p. 68). Por otro lado, siguiendo la tradición ilustrada alude a civilización al orden y al progreso y propone que hay que llenar los vacíos y luchar contra lo salvaje, "Se trata de ser o no salvaje." (SARMIENTO, 1874, p. 16). Al Facundo lo anima un fuerte motor político ilustrado y prescriptivo por ello enfatiza que es preciso superar la

\footnotetext{
$8 \quad$ Primer movimiento intelectual argentino que surge en el siglo XIX más precisamente en 1837 con la creación del Salón Literario. Tiene vigencia desde 1837 a 1880 momento durante el cual su ideología romática alcanza una hegemonía cultural. (TERÁN, 2015, p. 61).
} 
barbarie (TERÁN, 2015, p. 84). De allí que se encuentra organizado en un sistema semántico tendiente, por un lado, a la profundización y multiplicación de antagonismos (civilización / barbarie), y por otro a forzadas conexiones (ciudad es civilización / el campo es barbarie). “Una doble poética de la escisión social y del anclaje de significados, respectivamente relacionados a ese racismo y a ese autoritarismo que preside el espíritu argentino desde sus inicios hasta la actualidad." (BALER, 2003, p. 1).

Como señalaba inicialmente una influencia central en el Facundo y en el proyecto político de Sarmiento es el pensamiento de Tocqueville. Veamos qué nos dice Sarmiento (1874) en los inicios del ensayo: "A la América del Sur en general y a la República Argentina sobre todo, le ha hecho falta un Tocqueville" (p. 14). Desde mi punto de vista, esta no es una afirmación sin importancia, pues en la tradición ilustrada de Tocqueville el racismo junto con la idea de igualdad conforman un todo en la teoría sobre la democracia y así lo entiende Sarmiento: Las razas americanas viven en la ociosidad, i se muestran incapaces, aun por medio de la compulsión, para dedicarse a un trabajo duro y seguido. Esto sugirió la idea de introducir negros en América, que tan fatales resultados ha producido (Sarmiento, 1874, p. 26).

Él como tantos otros intelectuales americanos y europeos establecieron un imaginario del otro, un imaginario ficcional y una ideología en que mostraron al "otro" (indio, gaucho, negro) como cruel y brutal. En el Facundo todo lo relacionado con el gaucho es negativo (TERÁN, 2015, p. 78). En continuidad con este derrotero en su discurso en el Senado de la Nación deja claro quienes están en condiciones de ser pueblo en su concepción democrática:

Cuando decimos pueblo, entendemos los notables, activos, inteligentes: clase gobernante. Somos gentes decentes. Patricios a cuya clase pertenecemos nosotros, pues, no ha de verse en nuestra Cámara (Diputados y Senadores) ni gauchos, ni negros, ni pobres. Somos la gente decente, es decir, patriota. (SARMIENTO, 1857)

El Facundo condensa todas estas ideas. Es un libro escrito en "pro de la civilización, en pro de la modernidad y por ende en pro de una lógica de acción racional, según la cual se calculan los medios más adecuados para obtener los fines considerados valiosos" (TERÁN, 2015. p. 82). La civilización para Sarmiento se resume en: la ciudad, la raza blanca, el

\footnotetext{
$9 \quad$ “ $[\ldots]$ el mundo periférico colonial, el indio sacrificado, el negro esclavizado, la mujer oprimida, el niño y la cultura popular alienadas, etcétera (las 'víctimas' de la 'Modernidad'), como víctimas de un acto irracional (como contradicción del ideal racional de la misma Modernidad).” (Dussel, 2000, p. 43).
} 
progreso y las ideas; en contraposición está la barbarie que representa: la raza americana, la raza negra, el gaucho, el campo, la vida primitiva y la ignorancia. En sintonía con los análisis sobre la raza que nos propone Achille Mbembe (2012) se puede leer en el Facundo una idea de raza como un gesto que consiste en disolver al resto, al otro, en la cosa, el objeto o la mercancía, porque detrás del camino que le traza Tocqueville Sarmiento se empeña en construir un Estado Nación democrático liberal e igualitario pero a partir de la eliminación física de gauchos, indios y negros.

Tal como señala Oscar Terán, el Facundo le resulta a Sarmiento un discurso eficaz para implantar "[...] una serie de tópicos para pensar la realidad argentina" (2015, p. 67), en esta obra plasma los principios ordenadores de la construcción de la Nación argentina. Nación que solo será perdurable si logra producir nuevos sujetos civilizados por medio de la educación. "Educar al soberano" resulta la fórmula sarmientina que organiza una discursividad escolar (que si bien ha sido modificada y está en permanente tensión a lo largo de su historia durante el siglo XX) persiste en ella una colonialidad del poder-saber que silencia, oblitera y niega a los "otros".

\section{FREIRE: LA EDUCACIÓN POPULAR Y CAMPAÑA DE REACTIVACIÓN DE EDUCACIÓN DE ADULTOS EN ARGENTINA ( 1974-1976)}

Es a mediados del siglo XX que puede hallarse en la huella de las tradiciones resistentes al legado sarmientino y a las imposiciones eurocéntricas una crítica radical -desde América Latina- hacia el modelo educativo ilustrado y positivista implantado a partir del siglo XIX; la colonialidad del poder-saber comienza a ser discutida. Es Paulo Freire quien desde Brasil en los inicios de la década del 60 que con su pedagogía de la liberación propone como punto de partida un fuerte cuestionamiento a las formas de opresión presentes en la educación. Sus críticas inauguran un sentido otro para la educación popular y ponen bajo sospecha la racionalidad instrumental de la teoría-práctica educativa que olvida sistemáticamente al otro diferente.

Es a partir de este enfoque que Freire dialectiza los lugares de los sujetos en el proceso de enseñanza y de aprendizaje al articular los diferentes saberes de los que son 
portadores, sosteniendo a lo largo de toda su obra la siguiente afirmación: "El que enseña aprende y el que aprende enseña" (FREIRE, 2002, p. 28 apud FERNÁNDEZ MOUJÁN, 2019a, p. 92).

Esta definición de educación popular es asumida por sectores de la militancia social y política en la Argentina de fines de los años sesenta, y luego como política de Estado en la Campaña de Reactivación de Educación de Adultos (CREAR). Esta nueva concepción altera la práctica de la alfabetización de adultos, pues propone un cambio en el orden de los sujetos, un intercambio de lugares entre el sujeto educador y el sujeto educativo (PUIGGRÓS, 2013).

Observemos por un momento algunas cuestiones que traman este devenir histórico de la educación popular en sintonía con el legado freireano. Es a mediados del siglo XX en la huella de la tradición de los Simón Rodríguez, Martí, de la Revolución haitiana, de Mariátegui, de las revueltas campesinas y urbanas, y haciendo foco en la diferencia colonial irrumpe en la escena política la sospecha y la crítica radical -desde América Latina, Caribehacia el modelo ilustrado y positivista, que alcanza su máxima expresión cultural y política en los años 60 y 70 del siglo XX. Una resistencia al poder hegemónico que comenzó a ser expresada en otros términos; ya no alcanzaba con emanciparse y ser independientes. La tensión se presentó en el par liberación/dependencia (FERNÁNDEZ MOUJÁN, 2016). Los movimientos revolucionarios (compuestos por intelectuales, obreros y trabajadores) y los distintos gobiernos populistas de América Latina de aquellos años acompañaron este debate y sostuvieron la idea de que era posible la concreción de una revolución cultural.

En estos años en la Argentina germinan concepciones que van más allá de la resistencia se plantean un proceso que tiene como protagonista central al pueblo peronista, al peronismo revolucionario. Éste se plantea una política organizativa para transformar la sociedad y recuperar la experiencia política del peronismo de 1945-1955. Lo que se produce en Argentina en el seno de las organizaciones revolucionarias es un gran debate teórico-metodológico cruzado por las revoluciones cubana y argelina, las posiciones insurreccionalistas y de guerra popular prolongada, el foco armado y la política de cuadros en el marco de la constitución de un movimiento de liberación nacional. En estos debates están las figuras centrales de Ben Bella, Frantz Fanon, el Che Guevara, John William Cooke y José Hernández Arregui (DUHALDE y PÉREZ, 2003, p. 29, apud FERNÁNDEZ MOUJÁN, 2019b). En este clima de época llegan las obras de Paulo Freire a la Argentina. Leamos las 
palabras que pronuncia el Dr Héctor Cámpora, Presidente de Argentina, al inaugurar el $98^{\circ}$ Período Ordinario de Sesiones del Honorable Congreso Nacional 25 de mayo de 1973:

\begin{abstract}
Es un hecho cierto que toda revolución lo es en la medida en que se realiza como una revolución; y ése ha de ser el signo de la nuestra. Sin ella será imposible romper los lazos de la dependencia, establecer los pilares de la reconstrucción y avanzar victoriosamente en el camino de la Liberación. La colonización comienza siempre por la cultura, la descolonización es nuestra reconquista, ha de iniciarse también a partir de la cultura. En este sentido mi gobierno se compromete a consolidar la conciencia nacional mediante una definida integración de los valores espirituales, históricos, geográficos, sociales, económicos, intelectuales, científicos y artísticos de la Nación, en un estilo de vida de inspiración cristiana, de profundo contenido humano y de vivo sentido nacional, conforme al pensamiento del general Perón que dijo: aun pueblo sin cultura y conciencia social no es un pueblo, es una masa [...] El intelectual, el científico, el escritor, el artista, conscientes de la función social que les cabe, deberán aplicar su genio al acrecentamiento de la cultura del Pueblo y a la liberación de la Patria. (Libro de Actas del Congreso de la Nación, 1973, p. 50, vale lo extenso de la cita).
\end{abstract}

Las preocupaciones del Presidente Cámpora dialogan con la urgencia política que Paulo Freire condensa de manera clara y minuciosa en Pedagogía del oprimido (1970), obra en la que manifiesta la necesidad de realizar "[...] una transformación radical de la situación concreta de opresión." (FREIRE, 1970, p. 47). Lo que lo desvela es la viabilidad de una experiencia educativa que irrumpa descolonizando saberes impuestos, interrogando verdades dadas, en un intento de recrear el espacio educativo y hacerlo más humano. Dicho de otro modo, hace una invitación a asumir una praxis y un ejercicio vital que descolonice y desalinee el fenómeno educativo para revolver lo dado y tramar una resistencia cultural. En sus primeras palabras dedica su obra a: "A los desharrapados del mundo a los que en ellos se descubren y, así descubriéndose con ellos sufren, pero, sobre todo con ellos luchan”. Éste punto de partida es una toma de posición política al mismo tiempo que una invitación a interrogar la los basamentos de la educación. Y se pregunta más adelante:: “¿Cómo realizar entonces, la pedagogía del oprimido antes de la revolución?” (1970, p. 53). Tarea interpelante en la que Freire (1970) señala dos momentos distintos e interrelacionados. Un primer momento en que la tarea es el descubrimiento del mundo de la opresión/alienación y el compromiso con una praxis de transformación; un segundo momento de permanente expulsión de los mitos de la estructura opresora, de su conciencia dual que obtura e impide el desarrollo de los procesos de liberación (FREIRE, 1970, p. 54); para crear y sostener "la pedagogía de los hombres en proceso de permanente liberación" (FREIRE, 1970, 53) en una constante revisión crítica de la "violencia" pues: "El colonizado no deja de liberarse entre las 
9 de la noche y las 6 de la mañana. Esa agresividad manifestada en sus músculos va manifestarla el colonizado primero contra los suyos." (FANON, 1965 en FREIRE, 1970, p. 64)

Es interesante notar en este punto como comienza a publicarse en esos momentos la obra de Paulo Freire . La primera obra que se edita en Buenos Aires ${ }^{10}$ es La educación como práctica de la libertad en 1971 (Siglo XXI ${ }^{11}$ Argentina Editores, Buenos Aires en coedición con Tierra Nueva ${ }^{12}$, Montevideo); en 1973 se publica Pedagogía del Oprimido (Siglo XXI en coedición con Tierra Nueva); en 1974 Las iglesias, la educación y el proceso de liberación en la historia (Editorial Aurora, Buenos Aires) y Concientización (Ediciones Búsqueda, Buenos Aires); en 1975 Acción cultural para la libertad (Siglo XXI en coedición Tierra Nueva); 1975 Educación y Cambio (Ediciones Búsqueda, Buenos Aires). Cabe destacar que en 1973 la Editorial Carlos Lohlé de Buenos Aires en la colección Cuadernos Latinoamericanos publica con Traducción de Manuel Mercader el libro de James Cone Teología Negra de la Liberación cuyo prólogo es escrito por Freire. El pedagogo pernambucano ocupaba entre los intelectuales y militantes de campo popular en la Argentina de los años 60 y 70 un lugar de privilegio, sus obras eran leídas junto con Los condenados de la tierra de Fanon (1961). Freire recuerda así su visita a Buenos Aires en el año 1973:

En el mes de agosto de 1973 recibí una llamada de Buenos Aires. Era el jefe de gabinete del doctor Taiana, ministro de Educación. Me dijo que el propio ministro quería hablarme. "Profesor Freire-me dijo el doctor Taiana-, tendríamos mucho gusto si usted aceptase nuestra invitación de venir a Buenos Aries lo más pronto posible. Seria muy bueno, por ejemplo entre fines de este mes y comienzos de septiembre. era una revolución cultural estaba siendo hecha por un gobierno sin poder para tanto. Un trabajo en el campo de la educación sistemática, desde la escuela primaria hasta la universidad, y en el campo de la educación popular, de enorme riqueza y creatividad [...] Mi presencia de una semana en Buenos Aires se repartió entre dos encuentros de cuatro horas cada uno con los rectores de todas las universidades públicas del país, un encuentro de un día con todos los equipos técnicos del Ministerio, una reunión con un grupo popular en una zona periférica de Buenos Aires, y finalmente una trasnochada de militantes políticos en la que

\footnotetext{
10 Buenos Aires fue considerada por la mayoría de los militantes de izquierda chilenos y uruguayos que sufrían el exilio a partir de las dictaduras militares que vivían sus países. Era un lugar cercano, seguro, con posibilidades y muy próximo al estilo de vida que buscaba vivir un militante en los sesenta y setenta. Todo parecía indicar que Buenos Aires era lo suficientemente lejos para estar a salvo, lo suficientemente cerca para seguir en contacto estrecho con familiares y compañeros de la lucha política (BRUGALETTA, 2019, p. 107) 11 Siglo XXI, creada en México en 1965 por Arnaldo Orfila Reynal tras su polémico desplazamiento como director del Fondo de Cultura Económica. La propuesta editorial de Orfila Reynal se enmarcó en un proceso de "profesionalización de las ciencias sociales" y por la "avanzada política de izquierdas marcada por el tercermundismo y la revolución cubana. Además de sus sedes en México y Madrid, Siglo XXI instaló una filial en Buenos Aires en el año 1971” (BRUGALETTA, 2019, p. 120).

12 Editorial Tierra Nueva (1969-1973). Su director fue Julio Barreiro (1922-2005), uruguayo cristiano evangélico metodista que con el golpe de Estado en Uruguay se exila en Buenos Aires.
} 
discutimos lo que estaba sucediendo en el país [...] Recuerdo que discutíamos bastante sobre la cuestión política, así como sobre la cuestión epistemológica involucrada en el problema [...] colocar la universidad al servicio de los intereses populares [...] la relación entre sabiduría popular, sentido común y conocimiento científico (FREIRE, 1999, p. 181-183, vale lo extenso de la cita).

En este contexto se pone en marcha en la Argentina la CREAR. El esfuerzo de este campaña de alfabetización se concentró en abordar la transformación del discurso pedagógico civilizatorio, a partir del significante educación popular desde una perspectiva pedagógica ligada al pensamiento de Freire en articulación con la experiencia del gobierno popular de aquellos años. En sintonía con el legado freireano podemos leer en el epígrafe de los Lineamientos de la Campaña:

[...] cambiar el sentido de la enseñanza. El "enseñar" debe ser sustituido por el "aprender", por el aprendizaje integral. La pedagogía tradicional, la enseñanza del niño, debe ser sustituida por la enseñanza y el aprendizaje del hombre total. Se trata no de enseñar como de aprender, de llegar a la conclusión de que el mundo no se divide en educadores que saben y educandos que aprenden sino de reconocer que hay una estrecha interrelación. Nadie enseña en forma absoluta y nadie se limita a aprender, el que enseña también aprende y el que está aprendiendo está enseñando. Además, no hay edades fijas para aprender y edades fijas para aplicar lo que se aprendió. El hombre niño, adulto, anciano aprende desde que nace hasta que muere, en un proceso que no tiene interrupciones y en el cual el ser humano debe actualizarse, "reciclarse" permanentemente. (1974, p. 10, el resaltado es del original)

Ahora bien, cabe señalar que el antecedente central de esta campaña fue la experiencia de alfabetización de adultos de Angicos $^{13}$ (1963) coordinada por Paulo Freire. Este acontecimiento político no sólo dejará su huella en el Brasil, en el pueblo de Angicos, en la historia de la Universidad Federal de Pernambuco y en los hombres y mujeres que junto a Freire compartieron esta experiencia, sino que es un hito que marcará de manera insoslayable los caminos que recorrerá la educación popular en América Latina, en el Caribe y en los países africanos del occidente (FERNÁNDEZ MOUJÁN, 2016, p. 19). El programa de alfabetización que encaran Freire y su equipo en Angicos contó con un equipo de 21 investigadores y docentes de de filosofía, pedagogía, medicina, servicio social, odontología, derecho, biología y educación física desde la Secretaría de Extensión y Cultura de la Universidad de Recife. Fue con apoyo del gobierno nacional y del Estado de Río Grande del Norte. A partir de un trabajo colectivo propusieron un programa de alfabetización para 400 hombres, mujeres y jóvenes de Angicos que no sabían leer ni escribir, para ese momento del total de su población el 70\% era analfabeta y el 10\% de semi-analfabeta. La intención inicial 
era aportar al proceso populista que se vivía en el país y mostrar que era posible una educación política. En la primer etapa de investigación se propusieron recolectar el universo vocabular en conversaciones informales con la población y allí les comunicaban que ambos educadores y educandos serían sujetos del acto educativo no solo en el acto de descubrir el conocimiento sino también de recrearlo, de modo que les venían a proponer un acto de co-intencionalidad para alcanzar el conocimiento de la realidad a través de la acción reflexión en común. En una segunda etapa, siguiendo el método de palabra generadora y teniendo en cuenta el vocabulario de las gentes del pueblo partían de palabras simples a las más complejas junto a un soporte audiovisual. En cuanto a la organización de las clases: en la primera se realizaba el ejercicio de diferenciar entre un objeto de la naturaleza y un objeto de la cultura. A partir de allí se problematizaba la comprensión de la situación social y económica dentro de la realidad brasileña, a esta instancia de enseñanza-aprendizaje la llamaron: momento de politización. Con el correr de los días se incorporaban mayor cantidad de palabras y se iniciaba la construcción de oraciones. Se impartieron 40 clases durante 45 días. Un ejemplo de este acontecimiento fue la carta escrita y leída por una de las mujeres participantes del proyecto al Presidente de la República João Goulart quien concurrió personalmente al cierre de la campaña de alfabetización, testimonio que se encuentra en "Angicos. Diario de una experiencia" (1963):

Señor Presidente: En este momento tomo mi lápiz para comunicarle mis necesidades. Ahora mismo no soy más masa soy pueblo y por eso exijo mis derechos. Señor Presidente nosotros precisamos muchas cosas como: reforma agraria, escuela y que el señor vote las leyes de la constitución para poder salir de esta situación. Tengo dos hijas para educar y no tengo recursos por eso pido al señor una beca de estudio para que ellas no crezcan como yo crecí. (Francisca Andrade, 2 de abril de 1963).

En Argentina (diez años después) tras la huella de Angicos se lanza la campaña de la CREAR, esta condensa un demanda popular que conjuga el tránsito de los trabajos educativos en las tareas barriales $\mathrm{y}$, las actividades formativas de la militancia en diversos espacios sociales a una educación sistemática liberadora. Una acción en la que estuvieron involucrados miles de educadores-militantes de recorridos y experiencias diversas que confluían en torno a una consigna política "el pueblo educa al pueblo", una noción articuladora de educar para la liberación (NARDULLI, 2013, p. 37). Una política educativa que considera:

La educación de adultos es uno de los aspectos del proyecto general de educación que se inscribe a su vez dentro de la estrategia global de la Revolución Justicialista elegida por el pueblo e iniciada por el Gobierno Popular. El Gobierno se ha propuesto como meta irrenunciable producir profundas transformaciones que coloquen a la educación al servicio del proceso de la Reconstrucción y Liberación 
Nacional. Nuestra Revolución asume una política educacional que delimita como principal objetivo la liberación nacional, lo cual implica la nacionalización de la educación, que se define prioritariamente por la, construcción e integración a la dinámica social de los auténticos valores de la comunidad nacional. Esta es la descolonización cultural, que será definida en función de las líneas nacionales de nuestro pasado histórico y de las determinaciones que impone la conciencia colectiva de nuestro pueblo (CREAR, 2008, p. 12).

A partir de esta política de Estado en esos años se derivaron múltiples experiencias de educación popular que articuló la educación con la militancia política pues entre los requerimientos de esta intervención pedagógica estaba el compromiso militante. De ello dan cuenta las diversas historias de grupos que se multiplicaron a lo largo y ancho de la Argentina. Lo interesante de éstas fue que, por un lado, se fomentó una educación popular estrechamente ligada a lo político y a la participación activa de las barriadas y del campesinado; y por otro, la formación política de los coordinadores y educadores. Era efectivamente (con sus matices) la inclusión del pueblo en el proceso político-revolucionario que se vivía.

La coordinadora del área nos daba charlas. Nos explicaba lo que significaba trabajar con adultos, se lea me acuerdo la Pedagogía del Oprimido de Paulo Freire y se analizaba. En ese grupo que éramos todos alfabetizadores y había cierta heterogeneidad en el sentido de que por ejemplo uno estaba en la universidad, el otro no había un militante del barrio. Pero todos tenían un nivel de militancia política muy fuerte (MRP en NARDULLI, 2013, p.35).

Los coordinadores de base eran los alfabetizadores, y al mismo tiempo responsables de la dirección del proceso de alfabetización de cada centro de la Campaña. Se trabajó con los documentos que proveía la DINEA. Un proceso educativo que se propuso como objetivo central la formación de un sujeto político comprometido con las transformaciones de las estructuras injustas (económicas, sociales y políticas). De allí que las ideas que organizaron toda la intervención educativa: las formas educativas debían proceder del pueblo. Las ideas fuerza se sintetizaron en: participación, compañero-a, comunidad organizada, pueblo, organización de base, compromiso militante, identidad política como clase trabajadora (NARDULLI, 2013, p. 35-38). Al mismo tiempo que enseñaban y aprendían junto a otros compañeros del barrio se organizaban construyendo una guardería y la conexión de agua potable para todos. Lo interesante de muchas de estas experiencias fue el potencial político que dejó en quienes participaron de ellas. De acuerdo con Juan Pablo Nardulli (2013) en esta experiencia hubo tres pilares fundamentales, el compromiso militante de los participantes de la Campaña, la participación popular y la presencia efectiva-real de una política pública que 
impulsó estas acciones y puso a disposición del campo popular recursos y materiales simbólicos. Tal como lo sostiene Freire la acción pedagógica no es transformadora per se sino que se precisa compromiso, toma de conciencia y amor por los otros y es necesaria una agencia que "[...] no permite comportamiento ambiguos de quien la asume" (FREIRE, 1970, p. 62).

Un ejemplo de esta experiencia de educación popular como política de Estado fue experiencia de Villa Obrera en la Provincia de Neuquén, Argentina. En esta Elsa (la educadora) junto con mujeres y hombres trabajadores fue filmada por uno de los compañeros del grupo. Raúl, era fotógrafo profesional y se sumó con la intención de realizar una película que sirviera para otros barrios. Dos años más tarde del inicio de este trabajo se produjo en Argentina el cruento golpe militar de 1976 y el material filmado sufrió el exilio, pero 29 años después fue recuperado por el Grupo de Cine Mascaró quienes hicieron el documental Uso mis manos, uso mis ideas (2005). En documental se observa con claridad cómo la educación popular desde el marco que le proveyó Freire fue una efectiva concreción del esfuerzo de las clases populares a favor de la movilización popular con miras a la transformación de la sociedad. Los testimonios de los actores de aquel momento ante la pregunta que les dejó la experiencia de la CREAR en Villa Obrera responden: Queríamos aprender a leer y a escribir. Aprender ortografía. Conseguir un trabajo más digno. Concientizarse y terminar con la explotación. No ser engañados.

La co-implicancia propuesta por la educación liberadora freireana urdió la trama de la educación popular argentina desde mediados del siglo XX en adelante, articuló las acciones de educadores-intelectuales y las políticas públicas. A partir de ese momento en Argentina se estableció un diálogo intelectual fecundo con la posición político-pedagógica de Paulo Freire. Este diálogo se expresó en una racionalidad crítica que entrelazó lo racional y lo sensible, que disputó y puso en tensión una racionalidad instrumental heredada de la modernidad colonial. El “otro" ocupó en estas prácticas teorético-críticas un lugar de preeminencia, y adquirió un valor testimonial. Los y las educadoras populares argentinos(as) en diálogo con Paulo Freire entendieron la necesidad de recuperar el valor cultural y político del conocimiento; criticaron la teoría como un mero propósito y pusieron en práctica una educación liberadora con los(as) "condenados de la tierra" para revolucionar y transformar de la realidad injusta. 


\section{A MODO DE CIERRE}

¿Qué perdura del legado freireano en las prácticas de educación popular los movimientos populares surgidos al calor de la resistencia al modelo dictatorial y neoliberal impuesto desde 1976 en Argentina?

En la actualidad, la educación popular en la Argentina tras la tradición de Freire se ha ido reconfigurando y alude de manera heterogénea y dinámica a una diversidad de sentidos políticos y educativos que entrecruza propuestas de organizaciones populares diversas: indígenas, migrantes, de mujeres, de sectores urbano-populares, entre otras. Del mismo modo que en el resto de los países de la región, el resultado de ello son configuraciones sociohistóricas y culturales particulares: educación para el trabajo, formación política, artística, comunicacional, bachilleratos, apoyos escolares, alfabetización de adultos, etc. Acciones que llevan adelante los movimientos populares - urbanos y campesinos- en sus escuelas para niños y niñas, jóvenes y adultos, en centros de cultura, cooperativas, radios comunitarias y otros tantos ámbitos (GÓMEZ SOLANO; CADENA HERNÁNDEZ; FRANCO GARCÍA, 2013). Son prácticas que bregan por la toma de la palabra en los espacios de educación: el acento está puesto en la formación política de un sujeto colectivo, un nosotros histórico y de carácter transformador Se puede incluir aquí también las escuelas de formación política que facilitan y reafirman procesos de subjetivación política, asentados sobre la praxis política cotidiana que también es pensada como formación en sentido amplio. "Lo que articula en estas relaciones son las prácticas políticas de intervención directa en los asuntos comunes, así el compromiso individual se suma al proyecto común; y la aceptación de la política es reemplazada por la inquietud de lo político” (PALUMBO, 2015, p. 55).

Las experiencias de educación en los movimientos populares nos vienen a demostrar que la educación popular cobra sentido en el actuar cotidiano del pueblo, que entrelaza la militancia con la organización popular, desde un fuerte reconocimiento del legado freireano que articula procesos educativos meramente instrumentales junto con la formación política, la formación para el trabajo y la organización popular. Dicho de otro modo, la educación 
popular se encuentra liga estrechamente a su intencionalidad política y expresa la voluntad de transformación de lo real a partir de condiciones dadas, diseñando estrategias y tácticas que adquieren su sentido y legibilidad cuando son incorporadas a la lucha del pueblo. Como nos propone Mercedes Palumbo (2015), hay una variada trama de espacios-momentos formativos que abarca escuelas gestadas por los mismos movimientos populares para cubrir la ausencia del Estado en la garantía del derecho a la educación; talleres específicos de cultura, género, medios de comunicación con cierto grado de formalización y de regularidad en el tiempo; y una concepción de la integralidad de la militancia como formativa.

\begin{abstract}
En esta proliferación de espacios-momentos formativos también es posible rastrear un cuestionamiento a las formas básicas de la pedagogía moderna desde la praxis pedagógica: su lugar estabilizado en instituciones escolares públicas, la relación asimétrica maestro-alumno establecida en los términos de un ego magistral y un ente orfanal, y prácticas pedagógicas tradicionales nucleadas en torno a lo escolar"(PALUMBO, 2015, p. 52).
\end{abstract}

En la Argentina contemporánea la educación popular propuesta por Paulo Freire perdura y se renueva constantemente. Freire nos enseñó que en la educación popular no se puede descuidar la estrecha relación que existe entre la acción militante ligada al contexto de producción cultural, social, político y económico del pueblo. Que resulta necesario asumir(nos) sujetos hacedores de nuestra propia historia y desde allí generar otros discursos y otras prácticas tendientes a la transformación de un mundo injusto y a la producción de conocimientos otros.

En este sentido, las preguntas que recorren las acciones de educación popular giran en torno a las posibilidades de los des-aprendizaje y la emancipación de las conciencias. Señala Adriana Puiggrós (2013) al respecto:

La desobediencia al discurso escolar moderno y liberal está viviendo una nueva etapa en América Latina. La politización de la educación es una de las claves: abre inéditas perspectivas en el proceso de enseñanza y aprendizaje. Escuela y militancia no son incompatibles (p.12).

Prácticas de educación popular que interrogan nuestro territorio, nuestras prácticas culturales, nuestras memorias y cosmovisiones, y los haceres de los movimientos populares. Entre las múltiples experiencias que recorren Argentina (y nuestro continente) ubicamos las escuelas de nuestros pueblos originarios que apuestan a sus culturas como forma de supervivencia. O por ejemplo las pedagogías creadas y desarrolladas por militantes de 
movimientos populares. O, las propuestas de los movimientos de mujeres, experiencias colectivas que tiene como idea fuerza el cuerpo-territorio. Los talleres de educación y trabajo del Movimiento la Dignidad en la Ciudad de Buenos Aires, Licenciatura de Comunicación popular y comunitaria en la Universidad Campesina de la Movimiento Campesino de Santiago del Estero; los bachilleratos populares del IMPA (fábrica recuperada), el Bachillerato Mocha Celis (primer bachillerato popular travesti-trans), la Escuela de Agroecología de la Unión de Trabajadores Rurales Sin Tierra de Cuyo (San Juan y Mendoza). Éstas entre cientos de experiencias recorren nuestro país y entrelazan la formación política con el trabajo y la alfabetización, la comunicación, los problemas de violencia, etc. Muchas historias y prácticas que viven, sobreviven y resisten a la visión unilateral del mundo.. Prácticas que someten a crítica lo que podría denominarse la ideología de las teorías y prácticas educacionales tradicionales que con su fuerte contenido técnico-instrumental olvidan sistemáticamente al "otro".

En otras palabras, las prácticas teorético-críticas de educación popular en Argentina son tácticas de acciones cotidianas contrahegemónicas y (dis)ruptivas que no tienden a la totalidad sino que se saben débiles y contingentes. Acciones no de sujetos sujetados sino de resistencias subordinadas. En sintonía con Michel De Certeau (1996), practicamos una educación popular que se asume como fortaleza del débil y puesta en juego de su astucia, a partir de un entrometimiento insistente en los saberes, en los tiempos y en los espacios instituidos.

\section{FUENTES}

Angicos. Diario de una experiencia. Acervo Paulo Freire. São Paulo: Instituto Paulo Freire, 1963.

Discurso del Presidente de la Nación, Dr Héctor José Cámpora. Libro de Actas del Congreso de la Nación, Buenos Aires, 1973.

FREIRE, Paulo. Pedagogía del oprimido. Montevideo: Tierra Nueva, 1970, primera edición. FREIRE, Paulo. Pedagogía de la esperanza. México: Siglo XXI, 1999. 
Material de Apoyo del Método CREAR. Objetivos y contenidos para la etapa de reflexión en la alfabetización. Homenaje a la CREAR. Buenos Aires: Ministerio de Educación, Argentina, 2008.

SARMIENTO, Domingo Faustino. Facundo o Civilización i Barbarie en las Pampas argentinas, París: Librería Hachette, 1874 (cuarta edición).

TOCQUEVILLE, Alexis . La democracia en América, México: Fondo de Cultura, 1957.

\section{REFERENCIAS BIBLIOGRÁFICAS}

AÑÓN, Valeria y RUFER, Mario Añon. Lo colonial como silencio, la conquista como tabú: reflexiones en tiempo presente. Tabula Rasa, (29), 2018, p. 107-131.

BALER,Facundo. Civilización y Barbarie: Panfleto Épico. Apuntes para una poética del racismo, el autoritarismo y la egomanía en la Argentina. Everba, Summer, 2003, p. 1-8.

BHABHA, Homi. El entre-medio de la cultura. En HALL, Stuart. y DU GUY, Paul. (comps.). Cuestiones de identidad cultural. Madrid: Amorrortu, 2003.

BHABHA, Homi. El lugar de la cultura. Buenos Aires: Manantial, 2007.

BRUGAletTA, Federico. Tierra Nueva (1969-1985). Protestantismo de izquierda, edición y educación en la historia reciente de América Latina. Tesis de Maestría Universidad Nacional de La Plata, Facultad de Humanidades y Ciencias de la Educación, Memoria Académica, 2019. Disponible en: http://www.memoria.fahce.unlp.edu.ar/

DAVID, Guillermo. El indio deseado. Del dios pampa al santito gay. Buenos Aires: Las cuarenta, 2008.

DE CERTEAU, Michel. La invención de lo cotidiano. El arte de hacer. Tomo I. México: Universidad Iberoamericana, 1996. 
DE OTO, Alejandro; CATELLI, Laura. Sobre colonialismo interno y subjetividad notas para un debate. Tabula Rasa, (28), 2018, p. 229-255. Doi: https://doi.org/10.25058/20112742.n28.10

DUSSEL, Enrique. Europa, modernidad y eurocentrismo. En: LANDER, Edgardo (ed.). La colonialidad del saber: eurocentrismo y ciencias sociales. Perspectivas latinoamericanas. Buenos Aires: CLACSO, 2000, p. 41-43.

FERNÁNDEZ MOUJÁN, Inés. Elogio de Paulo Freire. Sus dimensiones ética, política y cultural. Buenos Aires: Noveduc, 2016.

FERNÁNDEZ MOUJÁN, Inés. Educación popular. FIORUCCI, Flavia; BUSTAMANTE VISMARRA, José. Palabras claves en la historia de la educación argentina. Buenos Aires: Universidad Pedagógica Nacional, 2019a, p. 121-122.

VISMARRA, José. La idea de revolución en la Pedagogía del oprimido. Dossier Paulo Freire a 50 años de Pedagogía del Oprimido. Archivos de Ciencias de la Educación, Universidad Nacional de La Plata, 2019b (en prensa).

GOMEZ SOLANO, Marcela; CADENA HERNÁNDEZ, Beatriz; FRANCO GARCIA, Josefina. En Rodriguez Lidia (comp.) Educación popular en la historia reciente en Argentina y América Latina. Aportes para balance y prospectiva. Buenos Aires: APPEAL, 2013.

HALL, Stuart. Notas sobre la deconstrucción de lo popular. Discurso y Poder. Huancayo: Ricardo Soto Sulca editor, 2013.

NARDULLI, Juan Pablo. 2013. Militancia y educación de adultos en la Argentina de los setenta: Notas sobre la Campaña de Reactivación Educativa de Adultos para la Reconstrucción (CREAR). Encuentro de Saberes. Luchas populares, resistencias y educación. Año II, No 3, 2013, p. 31-38.

PALUMBO, Mercedes, Las propuestas de formación política en movimientos populares entre la pedagogía y lo pedagógico. Intersticios de la política y la cultura. Intervenciones latinoamericanas, Vol. 3 Núm. 6, p. 2014, p. 51-65, 
Disponible en: https://revistas.unc.edu.ar/index.php/intersticios

PUIGGRÓS, Adriana. Enfoques de la educación latinoamericana en el siglo XXI. En Rodríguez Lidia (comp.) Educación popular en la historia reciente en Argentina y América Latina. Aportes para balance y prospectiva. Buenos Aires: APPEAL, 2013.

PUIGGRÓS, Adriana. Sujetos, disciplina y currículum en los orígenes del sistema educativo argentino. Buenos Aires: Galerna, 1990.

RIVERA, Andrés. El Farmer. Buenos Aires: Alfaguara, 2009.

TENTI FANFANI, Emilio. La escuela y la cuestión social. Ensayos de sociología de la educación. Buenos Aires: Siglo XIX, Primera Edición, 2007.

TROUILLOT, Michel. Moderno de otro modo . Lecciones caribeñas desde el lugar del salvaje. Tabula Rasa, (14), 2011, p. 79-97. 